\title{
Avaliação Psicológica na Educação Especial na Perspectiva da Educação Inclusiva
}

\author{
Alexandra Ayach Anache ${ }^{1}$ \\ ${ }^{1}$ Universidade Federal de Mato Grosso do Sul, MS, Brasil.
}

\begin{abstract}
Resumo: Este artigo tem como principal objetivo apresentar proposições sobre o processo de avaliação psicológica de indivíduos com deficiência intelectual na perspectiva histórico-cultural, considerando as pesquisas realizadas neste campo. Para esse fim, optou-se em realizar um ensaio acadêmico que visa apresentar e discutir os processos avaliativos na perspectiva histórico-cultural, baseado em livros clássicos dos autores com essa afiliação teórica, artigos publicados em periódicos científicos da área e áreas afins os quais foram balizados com a nossa experiência profissional. Destarte, organizamos este texto em dois eixos temáticos, sendo que o primeiro apresenta os elementos teóricos assumidos neste estudo e o segundo, referem-se às proposições para realização da avaliação psicológica de indivíduos com deficiência intelectual, caracterizando-a como avaliação-intervenção, alinha-se com três princípios do método instrumental proposto por Vygotski (1996), a saber: 1) análise do processo e não do objeto; 2) análise explicativa e não descritiva; e 2) a análise genética, do processo de desenvolvimento do indivíduo para construir explicações sobre a sua dinâmica psicológica.
\end{abstract}

Palavras-chave: Avaliação Psicológica, Educação Especial, Educação Inclusiva.

\section{Psychological Assessment in Special Education in the Perspective of Inclusive Education}

\begin{abstract}
This paper has as main objective to present propositions about the process of psychological assessment of individuals with intellectual disability using the historical-cultural perspective, considering the previous studies carried out in this field. To that end, an academic essay was designed to present and discuss the evaluation processes in the historical-cultural perspective, based on the authors with this theoretical affiliation classic books, papers published in peer-reviewed journals of the area and related areas. Thus, we organize this text in two main topics: the first presents the theoretical elements assumed in this study and the second refers to the propositions for performing the psychological assessment of individuals with intellectual disability, characterizing it as an evaluation-intervention aligned with three principles of the instrumental method proposed by Vygotski (1996), namely: 1) analysis of the process and not of the object; 2) explanatory and non-descriptive analysis; and 3) the genetic analysis of the development process of the individual to construct explanations about their psychological dynamics.
\end{abstract}

Keywords: Psychological Assessment; Special Education; Inclusive Education 


\title{
Evaluación Psicológica en la Educación Especial en la Perspectiva de la Educación Inclusiva
}

\begin{abstract}
Resumen: Este artículo tiene como principal objetivo presentar proposiciones sobre el proceso de evaluación psicológica de individuos con discapacidad intelectual en la perspectiva histórico-cultural, considerando las investigaciones realizadas en este campo.. Para este fin, se optó en realizar un ensayo académico que busca presentar y discutir los procesos de evaluación en la perspectiva histórico-cultural, basado en libros clásicos de los autores con esa afiliación teórica, artículos publicados en revistas científicas del área y áreas afines, con nuestra experiencia profesional.. De este modo, organizamos este texto en dos ejes temáticos, siendo que el primero presenta los elementos teóricos asumidos en este estudio y el segundo, se refiere a las proposiciones para la realización de la evaluación psicológica de individuos con discapacidad intelectual, caracterizándola como evaluación-intervención, que se alinea con tres principios del método instrumental propuesto por Vygotski (1996), a saber: 1) análisis del proceso y no del objeto;2) análisis explicativo y no descriptivo; y 2) análisis genético del proceso de desarrollo del individuo para construir explicaciones sobre su dinámica psicológica.
\end{abstract}

Palabras clave: Evaluación Psicológica; Educación Especial; Educación Inclusiva.

\section{Introdução}

Considerando que esta edição da Revista Ciência e Profissão é parte da agenda de comemoração dos 15 anos de existência do Sistema de Avaliação Psicológica (Satepsi) do Conselho Federal de Psicologia (CFP), a qual tivemos a honra de acompanhar desde sua instalação até os dias atuais, entendemos como oportuno apresentar as nossas contribuições sobre os impactos deste Sistema na proposição da avaliação psicológica destinada às pessoas que apresentam deficiências, mais especificamente àquelas que apresentam deficiência intelectual.

Desde a década de 1980, os processos avaliativos e os laudos que deles depreendem têm sido alvo de críticas, dentre as quais se destacaram que eles discriminam e excluem os indivíduos, que os métodos empregados não são adequados para o intento, sobretudo para compreender as suas condições de aprendizagem. Salazar (1996), Patto (1997), Anache (1997), Souza (2000), Machado (2002),

As pesquisas que realizamos sobre o uso da avaliação psicológica no contexto da educação especial, que visava realizar o encaminhamento de estudantes que estavam em situação de dificuldades de aprendizagem e experimentando vários anos de repetência, terminavam sendo encaminhados para os serviços de Educação Especial ${ }^{1}$, dentre os mais conhecidos na década de 1990 eram as classes especiais e as salas de recursos. $\mathrm{O}$ resultado deste trabalho, de forma surpreendente, demonstrou que não era especificamente a avaliação em si que discriminava as crianças, mas a forma pelo qual ela era conduzida, ou seja, a escolha, a aplicação, as análises dos resultados e a produção dos resultados finais, os quais eram materializados em forma de relatórios.

Aliada a esta situação, participamos de vários movimentos deflagrados e conduzidos por profissionais que também apresentavam as suas críticas aos modelos classificatórios dos processos avaliativos, quase que exclusivamente baseados em testes psicológicos, os quais na época não eram considerados válidos para a população brasileira (Anache, 1997, 2008, 2012). Essa situação era mais delicada quando se tratava de pessoas com deficiência intelectual, em decorrência das práticas aligeiradas, baseadas em julgamentos fundamentados na perspectiva dos déficits. Somavam-se a isso, as formas de interpretação

\footnotetext{
${ }^{1}$ Educação Especial: A Política Nacional de Educação Especial na Perspectiva da Educação Inclusiva (2008) conceitua a educação especial como sendo: “[...] uma modalidade de ensino que perpassa todos os níveis, etapas e modalidades, realiza o atendimento educacional especializado, disponibiliza os recursos e serviços e orienta quanto a sua utilização no processo de ensino e aprendizagem nas turmas comuns do ensino regular" (BRASIL, 2008, p. 11).
} 
baseados na perspectiva interacionista, o qual compreendido na época sob a lógica instrumental empregavam-se as provas piagetianas para avaliar o nível de desenvolvimento da criança, contrariando os pressupostos teóricos de Jean Piaget, ou seja, essas provas eram transformadas em testes.

As críticas relacionadas à avaliação no contexto educacional se avolumavam tanto por parte dos pesquisadores Patto (1997), Anache (1997), Souza (2000) e Machado (2002), integrados à associações científicas e pelo Sistema Conselhos Federal de Psicologia, resultando em uma força tarefa para promover estudos e pesquisas sobre os instrumentos de avaliação, dentre os quais se destacaram os testes psicológicos. Assim, em 2003 foi criado o Satepsi, e a Resolução CFP $\mathrm{n}^{\circ} 002 / 2003$ definiu e regulamentou o uso, a elaboração e a comercialização de testes psicológicos, revogando a Resolução CFP n ${ }^{\circ}$ 025/2001.

Estas ações impactaram a categoria e provocaram maiores investimentos na área da avaliação psicológica, considerando os seus contextos e os seus propósitos (Anache, \& Correa, 2010). No entanto, Santos, Anache e Santana (2015) realizaram investigação metacientífica das publicações nacionais do período de 2003 a 2012 sobre avaliação psicológica e encontraram 696 artigos obtidos por meio das indexadoras Index-Psi, Pepsic, Lilacs e SciELO. Eles concluíram que:

de 2003 a 2008 e sua subsequente desaceleração nas publicações; b) a alta concentração de produção no sudeste do país; c) a predominância dos estudos empíricos para o desenvolvimento de instrumentos; d) o foco nos campos da Psicologia Clínica, Psicologia da Saúde e Psicologia Escolar; e e) a ausência de trabalhos que exponham a articulação e integração de dados no processo avaliativo (p. 557).

Mais recentemente, até junho de 2018 foram acessados com o descritor de busca "Avaliação Psicológica" 6.157 trabalhos registrados no Banco de Teses e Dissertações da Coordenação de Aperfeiçoamento de Pessoal de Nível Superior (Capes), sendo que com o descritor "avaliação psicológica" da deficiência intelectual encontramos 10 trabalhos registrados, o que consideramos ainda incipiente.

De todo modos observam-se o crescente movimento da categoria, representada pelo CFP e pelas Associações Científicas para tornar a avaliação psico- lógica alinhada com os princípios dos Direitos Humanos, e, sobretudo, inclusiva em todos os segmentos em que ela se insere, conforme o disposto na Resolução CFP no 009/2018.

Neste percurso, os investimentos para construção de propostas de avaliação psicológica de indivíduo que apresenta deficiência intelectual ainda tem sido desafiadora, tanto no que se refere às características do público, quanto às dificuldades de encontrar métodos e técnicas adequadas para o intento. Sobre isso, lembramos que o conceito de deficiência pode adquirir várias compreensões, dentre as quais se destacou a versão patologizante, apoiada exclusivamente em explicações biológicas exaradas pelos diagnósticos médicos-psiquiátricos - hegemônicos no âmbito da história da Educação Especial brasileira (Kuhnen, 2017).

De todo modo, os processos avaliativos deste público e os diagnósticos que deles depreendem ainda tem sido um assunto que deveria ser mais estudado, conforme demonstrou o estudo de revisão de literatura realizado por Tezzele (2017) que realizou um balanço das produções acadêmicas com sobre a deficiência intelectual de1993 a 2015. Embora essa autora tenha encontrado maior concentração de trabalhos sobre o diagnóstico na área de saúde e sobre a escolarização na área de educação e Psicologia, informou que o tema "diagnóstico da deficiência intelectual" foi abordado por um trabalho, o que lhe surpreendeu, por ser um tema polêmico na área Concordamos com Tezzele (2017), pois desde a defesa da nossa tese de doutorado em 1997, estamos acompanhando as produções neste campo de referência e observamos que esta situação se agudizou.

A maioria das críticas em torno dos processos avaliativos partiu da perspectiva histórico-cultural, baseadas nos estudos de Vygotski (1996; 1997) e Luria (1981, 1991) os quais buscaram construir subsídios para avançar na perspectiva da avaliação-intervenção (Aguiar, 2015; Anache, 1997; 2012; Anache, \& Luz, 2014; Anache, \& Nuernberg, 2015; Facci, \& Souza, 2014; Lessa, 2014). Registre-se que nesta área, por ser interdisciplinar, é possível encontrar trabalhos que alinham seus campos de conhecimento neste contexto, como é o caso da Psicologia.

Se retomarmos a história da Educação Especial, a Psicologia sempre esteve pressente com o propósito de identificar e posteriormente oferecer conhecimentos sobre as características dos processos mentais de indivíduos com deficiência intelectual, e contribuiu 
sobremaneira para produção de concepções conceituais a respeito deste público nas políticas educacionais brasileiras (Jannuzzi, 2004). Ao fazermos uma retrospectiva, acompanhando o as contribuições de (Kuhnen, 2017), observou-se que os estudiosos desta área também participaram das críticas sobre as concepções de deficiências nas políticas nacionais desde 2000, denunciando, o seu caráter organicista e psicologizante de algumas correntes teóricas predominantes neste campo, e propunham o conceito de deficiência como expressão da "[...] diversidade cultural, dicotomizando a relação entre biológico e social ao criticar a medicina. Contraditoriamente, utilizavam-se da medicina para fazer o diagnóstico e o encaminhamento para o atendimento educacional especializado" (Kuhnen, 2017, p. 341).

Essa crítica foi realizada em um contexto de disputas político-ideológica em uma agenda de proposituras alinhadas com políticas neoliberais ${ }^{2}$, e com isso, a deficiência continuava [...] "sendo definida em relação a sujeitos que desviam para mais e para menos em termos de padrões físico, social, comportamental e que precisam de serviços especializados" (Kuhnen, 2017, p. 341). Assim, a Psicologia e a pedagogia se articulavam como o médico-psiquiátrico desde o início do século XX, participando da criação dos serviços de saúde escolar. Estes aspectos demonstram os desafios que encontramos nos processos avaliativos de indivíduos com deficiências intelectuais, sobretudo as consideradas mais severas.

Embora que as recomendações da Associação Americana de Deficiência Intelectual e Desenvolvimento (AAIDD) represente avanço ao reconhecer os múltiplos fatores determinantes da deficiência intelectual, sugerem um conjunto de instrumentos/testes para esta finalidade, os quais nem sempre podem ser aplicados para este público, em decorrência das suas diversas características. Em tempo, esta Associação considera como deficiente um indivíduo que apresentar déficit de inteligência (QI abaixo de 70), déficit em duas ou mais áreas do comportamento adaptativo, e, a depender da etiologia, pode se manifestar até os 18 anos de idade. Assim, o processo avaliativo deve ser realizado por meio da combinação de instru- mentos psicométricos e outros métodos de natureza qualitativa, evitando-se com isso, as inferências dos profissionais na elaboração das análises dos resultados (AAIDD, 2010).

Ainda que se relativize o peso dos instrumentos psicométricos neste processo, as análises das informações ainda se baseiam em resultados de desempenho das propostas de atividades que o indivíduo não conseguiu fazer, conferindo-lhe o status de déficit em relação ao seu grupo de referência.

Diante do exposto, buscamos outros modos de construir informações sobre o indivíduo, que se encaminha na perspectiva de subsidiar o seu processo de aprendizagem por meio da análise das atividades propostas em contextos naturais ou em intervenções preparadas de acordo com as características de cada pessoa, visando contribuir para o planejamento educacional prevendo os suportes necessários à sua educação. Para esse fim, a perspectiva histórico-cultural tem sido referenciada para identificar as possibilidades de aprendizagens e as funções psicológicas que nelas se implicam.

Ancorada nos ensinamentos de Vygotski entende-se a deficiência intelectual ${ }^{3}$, como um fenômeno que se constitui na relação intricada entre o social e o biológico, rompendo com a perspectiva intelectualista que ainda inspiram os laudos e pareceres ${ }^{4} \mathrm{da}$ área. Assim, os estudos sobre a metodologia no referencial teórico citado são relevantes por assumir o método dialético, o qual:

supõe o estudo do objeto em todas suas relações mediatas e, ante tudo, a revelação das relações substanciais, as relações dos fenômenos e das regularidades, a análise do estudado e em desenvolvimento, o descobrimento das contradições, a unidade da luta de contrários, o trânsito de quantidade em qualidade. O enfoque histórico é necessário aos métodos da psicologia (Petrovsky, 1981, p. 112).

Este artigo tem como principal objetivo apresentar proposições sobre o processo de avaliação psicológica de indivíduos com deficiência intelectual na perspectiva histórico-cultural, considerando

\footnotetext{
${ }^{2}$ Neoliberalismo fundamenta-se no Liberalismo Econômico Clássico, o qual defende que o Estado deve ter mínima participação nas atividades econômicas e sociais do país. Portanto a Educação deve se alinha com a lei de mercado, onde o estudante passa a ser considerado um consumido de ensino.

${ }^{3}$ Vygotsky (1997) usava o termo defectologia ao referir-se ao desenvolvimento incompleto.

${ }^{4} \mathrm{O}$ conceito de laudo e parecer estão contidos na Resolução que trata de documentos escritos.
} 
as pesquisas realizadas neste campo. Para esse fim, optou-se em realizar um ensaio acadêmico que visa apresentar e discutir os processos avaliativos na perspectiva histórico-cultural, baseado em livros clássicos dos autores com essa afiliação teórica, artigos publicados em periódicos científicos da área e áreas afins os quais foram balizados com a nossa experiência profissional. Destarte, organizamos este texto em dois eixos temáticos, sendo que o primeiro apresentará os elementos teóricos assumidos neste estudo, aliados à s produções acadêmicas que se encaminharam sob este ponto de vista e a seguir, apresentaremos as proposições para realização da avaliação psicológica de indivíduos com deficiência intelectual.

\section{Os fundamentos e desdobramentos dos estudos da deficiência intelectual da perspectiva histórico-cultural}

A preocupação desta abordagem não é diagnosticar a deficiência da pessoa, mas ao contrário, é produzir conhecimentos sobre as suas características psicológicas em consonâncias com as condições sociais de seu processo de desenvolvimento. Essa compreensão se baseia nos ensinamentos resultados dos estudos de Vygotski, com referência aos textos reunidos na obra "Fundamentos de Defectologia" (1997) e também de Luria (1981; 1991). Considerando os limites deste artigo, optamos em apresentar alguns princípios que sustentam a construção da proposta de avaliação, os quais se destacam: a perspectiva social da deficiência e a observância aos aspectos qualitativos implicados na constituição dos processos psicológicos superiores.

As pessoas percebem as suas dificuldades e limites na relação com o outro. (Vygostski, 1997). Certamente, o autor está atribuindo importância nas condições concretas de vida, onde circulam valores e conhecimentos fundamentados predominantemente na abordagem biologicista e quantitativista, a qual atribui maior valor na performance do indivíduo, comparando-o ao seu grupo de referência. Assim, o nível de desenvolvimento atípico e comparado com o nível de desenvolvimento típico.

No contraponto desta orientação, Vygotski (1997) foi enfático em afirmar que o indivíduo com deficiência se organiza de formas adversas, a depender das suas condições concretas de vida. Não há linearidade na relação entre os fatores externos e internos na formação dos processos psicológicos superiores. Portanto, entende-se como relevante atentarmos para a situação social de desenvolvimento do indivíduo, pois ela é considerada como ponto de partida para compreensão das relações (trocas) que se produzem no processo de desenvolvimento nas diferentes etapas da vida.

No que tange aos processos avaliativos, concordamos com Mitjáns Martínez (2003, p. 80), quando afirmou que é necessário:

Mudar o foco de análise da deficiência concreta para o sujeito como um todo, considerando não apenas seus pontos fracos, mas suas características mais positivas, como fundamentado por Vygotsky (1989), permite considerar em primeiro plano a análise de sua constituição subjetiva, ponto essencial, ao nosso modo de ver, para compreender a suas potencialidades criativas e suas possibilidades de desenvolvimento.

Outro princípio relevante para avançarmos para a construção de avaliação dinâmica é a relação entre os conceitos de defeito primário e secundário. O primeiro refere-se à natureza biológica desta característica e o segundo é gerado a partir do impacto que o primeiro pode promover em seu contexto condições adequadas ou inadequadas para a educação. Sobre isso, Vygotski ensinou que o desenvolvimento insuficiente das funções psicológicas superiores, pode estar relacionado com as limitações impostas pelo meio em favorecer condições de aprendizagem dos bens culturais disponíveis. Devido a isso, as dificuldades da criança acumulam-se, agravando ainda mais esta situação, conforme os argumentos deste autor,

Nesta situação em que a criança se desenvolve tem recebido menos do que pôde, ninguém tem tentado vinculá-la ao meio; e se a criança está pouco vinculada e de um modo fraco, com o grupo infantil, aqui podem surgir complicações secundárias (Vygotski, 1924-1929/1989, p. 114).

Vygotski (1997) considerou relevantes os conceitos de compensação e supercompensação, por eles serem necessários para movimentar recursos internos do indivíduo mediante a condição de sua deficiência, considerando sempre as possibilidades que lhe são ofertadas na situação social de seu desenvolvimento. Essa complexa teia de relações implicadas na constituição psíquica é fonte de energia que contribui para 
a superação das dificuldades que os limites biológicos estabelecem no curso da vida.

A partir dos fundamentos do materialismo histórico dialético, Vygotski (1997) se contrapôs à ideia de Alfred Adler e definiu os conceitos de compensação e supercompensação, formulando a sua tese de que:

simultaneamente com a deficiência também estão dadas as tendências psicológicas de orientação oposta, estão dadas as potencialidades compensatórias para superar a deficiência e que precisamente são estas as que saem em primeiro plano no desenvolvimento da criança e devem ser incluídas no processo educativo como sua força motriz. [...] Crer que qualquer deficiência se compensará é tão ingênuo como pensar que qualquer enfermidade termina indubitavelmente na recuperação. Principalmente necessitamos de critério e realismo na valorização, sabemos que as tarefas da supercompensação de tais deficiências como a cegueira e a surdez são enormes, enquanto que o fluxo compensatório é pobre e escasso; o caminho do desenvolvimento é extraordinariamente difícil, mas, por isso, é tão mais importante conhecer a direção correta (Vygotski, 1997, p. 47).

Estudar o desenvolvimento de crianças com deficiência intelectual, denominada na época por Vygotski (1997) de "retraso mental" foi por ele considerado um desafio, por considerar difícil definir a essência a origem e o curso do desenvolvimento destes indivíduos, observando as leis que o regulam. Estas crianças adquirem características qualitativamente peculiares, as quais devem ser tomadas como processos, e, que, portanto, requerem a adoção de metodologias de análises que consigam captar o curso do movimento entre a condição primária da deficiência e a superação de novas formações psicológicas que se originam. Sobre isso, o autor alertou que a superação implica em colocar em ação vários recursos que depreendem da relação entre as dificuldades impostas pela própria deficiência e os mecanismos acionados no processo de adaptação ativa do indivíduo ao seu meio.

Assim, é necessário identificar quais são os aspectos psicológicos que trabalham a favor do desenvolvimento da criança, para que as carências possam ser supridas por meio de investimentos educacionais adequados. Em outros termos, é importante analisar as reações do indivíduo mediante as dificuldades pelas quais se depara, e como se reestrutura para se equilibrar como um todo. É a criança que apresenta a deficiência que o interessa e não a deficiência dessa criança, para saber quais são espaços que essa característica ocupa na sua constituição de seu psiquismo. As ações compensatórias se apresentam no curso do processo de desenvolvimento, em decorrência das relações que a criança vai estabelecendo com a sua cultura. Graças à plasticidade cerebral, as funções psicológicas superiores, como memória, atenção, percepções, pensamento, consciência vão se formando, movidas pelos processos de aprendizagens desde a formação dos primeiros hábitos até a atividade consciente do homem, o qual é carregado de emoções gerado pelas diferentes formas de afetos. Arce Hai (2018, p. 68) corroborou com esta ideia afirmando que " $[. .$.$] a plasticidade cerebral torna possíveis nos-$ sas diferenças culturais, que ganham corpo em respostas por vezes distintas ao aprendizado das áreas de conhecimento que constituem o currículo escolar".

O objetivo da avaliação psicológica no contexto educacional é promover informações relevantes sobre as características dos movimentos das funções psicológicas engendradas nos processos de aprendizagens dos indivíduos, promovendo com isso, a produção de metodologias adequadas para proporcionar condições para que a educação (formal e informal) promova o seu desenvolvimento. Nessa perspectiva, a avaliação deve se constituir como instrumento orientador sobre quais mediações (signos, símbolos e outros instrumentos) serão necessárias para evitar as práticas que enclausuram o indivíduo na condição de sua condição orgânica.

\section{Proposições para a realização da avaliação psicológica de indivíduos com deficiência intelectual}

A avaliação psicológica na perspectiva histórico-cultural tem sido alvo de vários debates em decorrência das críticas que Vygostki (1997) e Vygostki e Luria (1996) realizaram no curso de suas investigações, dentre os quais se destacaram aquelas relacionadas à psicometria empregada pelos psicólogos do seu tempo e também pela redução deste processo a uma razão instrumental, na qual se detinha em identificar as lesões do funcionamento cerebral. Não obstante, não podemos esquecer que na época a teoria da localização das funções cerebrais estavam presentes e pautavam a maioria das investigações sobre as lesões 
que os indivíduos que se tornavam deficientes em decorrências das guerras. Foi Luria (1981) que explicou que a função não pode ser entendida como sendo resultado do funcionamento de uma área particular, mas como um sistema funcional completo e complexo. Portanto, não se pode reduzir uma atividade cognitiva a poucos agrupamentos neuronais específicos, ou seja, o objetivo é saber quais são as regiões do cérebro que estão atuando em conjunto para construírem a atividade mental. A título de ilustração, Luria utilizou o exemplo de uma orquestra, a música resulta da composição de vários instrumentos, que possuem tempo e lugar para participarem do concerto. Os fenômenos psicológicos como atenção, memória, percepção decorrem da participação de diversas áreas cerebrais, as quais atuando de forma "orquestrada" proporcionam a função requerida. Ao diferenciar a localização de uma função e a localização de um sintoma especificamente a partir da análise de seus efeitos secundários, Luria argumentou que:

A aceitação pelo neurólogo de que os transtornos nesses processos mais complicados se manifestam principalmente nas lesões das zonas cerebrais delimitadas (por exemplo, os transtornos práxicos geralmente são resultados de danos nas regiões parietais inferiores, os transtornos da fala receptiva em lesões das regiões temporais superiores, enquanto que os transtornos da fala expressiva são vistos em lesões da zona inferior da região frontal superior, no hemisfério esquerdo) acarretou na aceitação implícita da hipótese de que as funções complexas estão localizadas nestas áreas delimitadas do córtex. Logo, dizer que a "localização de um sintoma" não é o mesmo que a "localização de uma função" tinha uma influência mínima (Luria, 1981), p. 19-20, destaques do autor).

Essa perspectiva requer que a avaliação psicológica de pessoas com deficiência intelectual avance para além dos sintomas expressos na forma de comportamentos inadaptados, como sendo resultantes de zonas corticais específicas e responsáveis exclusivamente de fenômenos psicológicos complexos que vem sendo desenvolvidos ao longo da história, como a capacidade de compreensão das ações que envolvem o uso da lin- guagem e, por conseguinte a fala e outras formas mais elaboradas de pensamento (Luria, 1991).

Entendemos que os processos psicológicos se constituem no movimento das relações estabelecidas no contexto sociocultural, os quais não movidos por afetos e emoções, implicadas nas diferentes formas de linguagem, conforme destacou González Rey (2012), pois ela é definidora da ação do sujeito ${ }^{5}$ ativo que expressam pelas diferentes formas de linguagem decorrente das vivências. Assim, cada um constrói recursos para responder às exigências sociais as quais estão expostos. Nesse sentido, não há como se apegar a um conjunto de regras universais que podem de alguma maneira justificar um comportamento considerado fora dos padrões esperados para a sociedade. Lembrando que todo processo avaliativo deve considerar a subjetividade dos envolvidos nele implicadas. A subjetividade caracteriza-se pela constituição de sistemas simbólicos e de sentido subjetivo, e esse se integra aos aspectos constitutivos da personalidade, como as vivências das situações que os sujeitos enfrentam; portanto, aprende-se, como sistema, e não somente com o intelecto. Dito de outro modo, quando o sujeito se envolve afetivamente em uma atividade, mobiliza emoções, simbolizações que se integram à história individual, movimentando o sujeito para novas aprendizagens "[...] Assim, os sentidos subjetivos são inseparáveis da complexidade da subjetividade do sujeito" (González Rey, 2006, p. 34). A subjetividade social da escola, da família e da comunidade integra-se à subjetividade individual do sujeito que participa desses espaços, e, nessa teia se integram e se constituem mutuamente. Portanto são nestes dois níveis que os sentidos subjetivos são produzidos, integrando-se nas configurações subjetivas do sujeito. Em tempo, González Rey $(2006 ; 2011 ; 2012)$ utiliza esse conceito com o objetivo de romper com a compreensão determinista de personalidade, vez que ela é dinâmica, se mobiliza e se transforma por meio das vivências, e nesse movimento, o sujeito produz novos sentidos subjetivos, agregando-os às configurações subjetivas existentes, os quais produzem novas configurações. Portanto, a personalidade é entendida como uma configuração de configurações.

O pensamento é função de sentidos subjetivos e, dependendo das experiências vividas, pode impulsionar novas aquisições e promover condições para a

${ }^{5} \mathrm{O}$ uso do termo "sujeito" refere-se ao ser ativo, relacional que se constitui na história de vida. 
superação das dificuldades experimentadas ao longo da vida do sujeito. Essa perspectiva exige mudanças nos encaminhamentos da avaliação, na medida em que valoriza as dimensões afetivas implicadas na aprendizagem. Interessa saber como o indivíduo se organizou mediante a sua condição que está na base da sua constituição. A nossa experiência nos permitiu afirmar que o desenvolvimento cultural da pessoa com deficiência intelectual decorre da falta de investimentos em suas possibilidades de aprendizagem. Muitas vezes elas recebem menos do que as suas capacidades lhes permitem, mantendo-se alijadas do grupo (Anache, 2012).

Para construir uma avaliação psicológica no contexto educacional é preciso considerar a situação social do desenvolvimento. Vygotski $(1996,1997)$ por ela representar o movimento de mudanças que ocorrem no desenvolvimento psicológico durante um dado período. Esse recorte temporal deve ser compreendido em sua dinâmica, a qual expressa a complexa trama entre a natureza/biológico e a criação/social.

Alinhada com três princípios do método instrumental proposto por Vygotski (1996), a saber: 1) análise do processo e não do objeto; 2 ) análise explicativa e não descritiva; e 2) a análise genética, do processo de desenvolvimento do indivíduo, construímos nossas proposições para a avaliação psicológica de indivíduos que apresentam deficiência intelectual.

$\mathrm{O}$ método instrumental se caracteriza por ser um método histórico-genético que visa estudar a história do comportamento. Este autor fez referência a ele em vários momentos de sua obra, dentre os quais se destacam estudos sobre o desenvolvimento das funções psicológicas superiores (Vygotski, 1997). Mais recentemente, Prestes, \& Tunes (2018) escrevem sobre o método pedológico $^{6}$, o qual foi utilizado por Vigostki (1997) para estudar as crianças com deficiência intelectual.

A procura por explicações sobre as condições pela qual afetam as crianças é um longo processo de peregrinação, o qual denuncia as dificuldades que as famílias ou responsáveis encontram no percurso. E quando encontram, recebem informações aligeiradas, confirmando o já sabido - o atraso, a dificuldade, o não aprender, traduzidos em um código pelos manuais de diagnósticos de transtornos e mesmo de doenças. Não obstante, reduz o indivíduo a essa condição, para receber algum tipo de tratamento ou mesmo educação especial.

Considerando que "o método é, ao mesmo tempo, pré-requisito e produto, o instrumento e o resultado do estudo" (Vygotski, 1984, p. 74), os nossos materiais e métodos devem ser escolhidos com a finalidade de pesquisar a história de vida do indivíduo, de sua família e dos lugares que ocupam no recorte espacial e temporal, sendo fundamental identificar os valores culturais implicados na subjetividade deste grupo, os quais se desenvolvem nas tramas das vivências do ser humano. Sobre isso, Anache e Luz (2014, p. 160) afirmaram que:

A reconstrução da história do sujeito com experiências vividas na condição de deficiente intelectual é recortada por vários fragmentos, que se inicia com as dúvidas e silêncios sobre as suas reais capacidades de poder viver com os limites impostos e, também, construídos ao longo de sua vida.

Vários instrumentos entram em cena, desde as entrevistas em suas formas variadas com os diversos participantes da vida do sujeito (pai, mãe, irmãos avós, cuidadores, professores, profissionais etc.), e, sobretudo, a própria pessoa, considerando inclusive os seus limites para se comunicar. Nessas situações, adaptamos os recursos como, por exemplo, materiais adaptados para idade e característica do sujeito, incluído, quando for necessário o uso de tecnologia assistiva $^{7}$. No processo de avaliação, recolhem-se documentos que podem adensar as informações sobre o percurso do sujeito. Nesta abordagem construímos o processo avaliativo de acordo com as características de cada situação, o qual se inspira na metodologia de estudo de caso.

Neste sentido, "os sintomas" são entendidos como sinais que movimentam o sujeito para buscar mecanismos compensatórios, os quais são fundamentais para dar "visibilidade ao invisível", eles não elementos que vem ser compreendidos na lógica da unidade, ou seja, na parte está contido o todo e essa é

\footnotetext{
${ }^{6}$ Nas explicações de Prestes (2010), usando o Dicionário Houaiss, a palavra "pedologia", etimologicamente, vem do grego para fazer referência ao estudo sistemático da vida e do desenvolvimento das crianças. Ela informou que este termo era proibido na antiga União Soviética, o que levou Luria a substituí-lo por Psicologia Infantil.

${ }^{7}$ Tecnologia Assistiva é considerada a área de conhecimento interdisciplinar, pois envolve várias áreas que estudam as características e as especificidades de cada deficiência, devendo estar integrada à proposta curricular da escola.
} 
parte constituinte dele. Góes (2000) corroborou afirmando que a expressão dinâmico-causal é entidade mutável, sendo que de modo dinâmico a causa pode se transformar em efeito e esse em causa.

Assim, cada sujeito que se apresenta à avaliação requer planejamentos específicos, pois se avalia a criança com deficiência e não a deficiência da criança. Vigotski (1996) nos ensinou que: se estuda o processo educativo que qualifica o sujeito em sua trajetória de vida com a finalidade de desvendar como se reestruturam as funções naturais, considerando as características educacionais as quais ela participa. Ele afirmou que "[...] o método instrumental procura oferecer uma interpretação acerca de como a criança realiza em seu processo educacional o que a humanidade realizou no transcurso da longa história do trabalho" (Vigotski, 1996, p. 99).

$\mathrm{O}$ uso das ferramentas é um forte indicador das características do desenvolvimento psicológico do sujeito, informando sobre a dinâmica do seu processo de aprendizagem, fundamental para a constituição da atividade consciente. Em tempo, a a aprendizagem é um sistema complexo, o qual envolve a tríade cognição-afeto-vida social. Portanto, o domínio dos bens produzidos pela humanidade (uso dos instrumentos) deve ser investigado pelo profissional com a finalidade de descobrir os "[...] instrumentos que estão implicados e do estabelecimento dos atos instrumentais" (Vigotski, 1996, p. 100). Os atos instrumentais referem-se à organização da psique mediante aos elementos culturais as quais o sujeito está exposto, os quais dizem respeito à singularidade da sua estrutura interna. Portanto, o ato instrumental fundamenta o método instrumental, pois o objeto/estímulo que movimenta o sujeito para se organizar e construir respostas para a situação que lhe é apresentada, se configura como ferramenta psicológica do ato instrumental (Vigotski, 1996).

Conduzimos os processos avaliativos identificando esta relação no curso da relação que vamos construindo com os sujeitos envolvidos, o que significa que esse percurso merece investimentos de tempo e de procedimentos que vão sendo construídos ao longo das intervenções, visando identificar o nível de desenvolvimento real, bem como as possibilidades de aprendizagem do sujeito, por meio das pistas ofertadas no processo das atividades proporcionadas. Nesse sentido, é possível compreender o valor que o conceito de Zona de Desenvolvimento Iminente ocupa nesta abordagem, 'pois ela possibilita por meio das relações dialógicas identificarem as neoformações das funções psicológicas em andamento. Esse conhecimento favorece ao profissional, condições para construção de estratégias adequadas para o nível de desenvolvimento psicológico do sujeito.

Para estudar as características psicológicas do sujeito valemo-nos da avaliação intervenção, por entender que os sujeitos se expressam nas diferentes relações que estabelecem no curso de suas vidas, portanto, não há como aplicar um único protocolo para todos, o que requer rigor metodológico na planificação de todas as etapas do processo. Portanto, é importante considerar que ele se organiza de forma complexa, onde se integram períodos críticos e períodos estáveis. Vygotski (1987, p. 151) o definiu como processo dialético, complexo, caracterizado por múltipla periodicidade e desproporcionalidade das diferentes funções, por transformações qualitativas de umas formas em outras, onde se entrelaçam e se implicam as relações entre os fatores externos e internos. Portanto, ganha especial valor a análise das vivências como unidade de estudo da relação entre as configurações subjetivas e o meio, permitindo ao profissional acessar os sentidos subjetivos que as experiências produziram no sujeito.

O sujeito deve ser estudado tanto do ponto de vista da sua constituição biológica, considerando-o como um sistema complexo, quanto do ponto de vista da utilização dos processos psíquicos naturais e “[...] das formas que essa utilização adota, procurando compreender como o homem maneja as propriedades naturais de seu tecido cerebral e como controla os processos que nele ocorrem" (Vygotsky, 1996, p. 95). Por essa via, as expressões comportamentais podem informar sobre as operações intelectuais, portanto, quando uma criança brinca imitando um adulto, pode-se observar um conjunto orquestrado de funções psicológicas, como memória, atenção, pensamento, afetos e ainda é possível prospectar sobre suas possibilidades de aprendizagem.

Os instrumentos devem ser adequados às possibilidades de manuseio do sujeito. No caso de crianças com deficiências intelectuais mais graves, deve-se observar se ela não consegue usá-los pelos limites impostos pela sua condição ou se não lhe foram oportunizadas para que possa fazê-lo. Como já afirmamos anteriormente, esta é uma situação muito presente na vida destas pessoas. 
O processo de diagnóstico deve observar a sua história e a plasticidade variável de suas capacidades, para possibilitar-lhe um trabalho que venha levá-lo a superar o "defeito", acionando o mecanismo de compensação (Vygotski, 1996). Esse mecanismo permite ao sujeito reestruturar-se para compensar a deficiência natural através de atividades, ou mesmo através do uso de sua função que (se ela for fraca) ou de funções substitutas (se forem ausentes). Assim, é imprescindível que o psicólogo consiga descobrir junto com os professores, crianças e familiares, como ele constrói e elabora os seus conhecimentos considerando as suas características culturais e sociais. A triangulação desses elementos são subsídios para que o profissional possa construir informações junto com os envolvidos. Nessa perspectiva o processo avaliativo é uma construção compartilhada. Nesse referencial, é necessário que se estabeleça a relação entre os dados empíricos e os aportes teóricos que sustentam as explicações.

Os informes vão sendo construídos no curso da ação do processo avaliativo, onde é possível, por meio da relação dialógica promover e aprofundar discussões a respeito da condição do sujeito. Assim vamos promovendo para que todos os envolvidos se constituam em sujeitos da ação, e assim, este processo se apresenta como ato educativo, visando transformar a situação que ora se apresenta.

No contexto da educação especial é importante estreitar as relações com os professores, sobretudo com aqueles que realizaram os encaminhamentos para a avaliação. Sugere-se pesquisar a criança da escola e a escola da criança, e para isso é necessário que se incluam as versões das professoras, familiares e da própria criança e a escola para que o diagnóstico psicológico não colabore para o aprofundamento do preconceito sobre as impossibilidades de aprendizagem destes sujeitos. Anache (1997) já informava sobre a necessidade de estreitamento do vínculo entre o psicólogo e a escola visando o acesso às informações sobre a participação de crianças com deficiências nestes ambientes. Esse encaminhamento também foi referendado por Lessa (2014) quando estudou as funções psicológicas superiores de estudantes com queixas escolares, inspirando-se no método instrumental de Vygotski (1996) quando afirmou que se pode valer de experimentações e observações e outros recursos para avaliar a memória, a atenção, a formação de conceitos, as expressões de pensamento etc. na perspectiva de identificar o nível de desenvolvi- mento do sujeito e oferecer informações para aqueles que atuam junto ao estudante sobre as condições de aprendizagem dela.

Anache (1997) alertou para que se tenham cuidados ao retirar o aluno da sala de aula, para que a criança não seja exposta aos colegas de turma. Essa conduta exige dos psicólogos certa convivência na escola, o que poderá ser planejado de acordo com as possibilidades do grupo. Esse contato poderia viabilizar a participação do mesmo nas atividades da classe, para que ele possa visualizar a criança que se apresenta com dificuldades em interação com o seu grupo, bem como a interação do mesmo com ela.

A escuta da criança pode ser realizada em vários encontros individuais e em grupos, com o objetivo de o psicólogo familiarizar-se com ela. Do conteúdo dessas reuniões, deverão ser extraídas as estratégias para o planejamento do diagnóstico psicológico, ou seja, é necessário que esteja claro para eles: como, por que, quando e qual instrumento utilizar. Nesse sentido, o psicólogo precisa ter conhecimentos técnicos para escolher os instrumentos básicos para esse trabalho, não se limitando exclusivamente à aplicação de testes psicológicos. Em tempo, esses instrumentos devem ser planejados de acordo com as possibilidades de cada sujeito, com o objetivo de serem empregados como indutores, visando analisar a qualidade das formulações do pensamento que motivou a expressão das repostas a eles.

Portanto, faz-se necessário construir formas de comunicação acessíveis para obter respostas às perguntas, o qual requer acompanhamento, observações e registros das mais variadas situações. Essa prática possibilitará à criança uma certa mobilização pelo fato de que uma atenção especial foi dedicada a ela, não deixando de ser uma intervenção na sua dinâmica pessoal e consequentemente escolar e familiar. Collares, \& Moysés (1997, p. 25) nos ensinaram que:

Esta forma de avaliação tem o sentido inverso dos testes padronizados, em que uma atividade previamente estabelecida é a única forma aceita para avaliar uma determinada capacidade. Ao invés de a criança ter que fazer o que o avaliador sabe avaliar, é o avaliador que tem que enfrentar o desafio de transformar em avaliação o que a criança sabe e gosta de fazer. A objetividade de um teste não é maior do que a forma proposta, pois a subjetividade se coloca, não pelo instrumento, mas pelo pesquisador enquanto homem, ser social. 
Cada criança tem um estilo peculiar de se relacionar com as exigências impostas pelo grupo social, portanto, é importante analisar suas reações em situações diferenciadas, como por exemplo, se ao executar uma tarefa, ela agirá com perseverança, ou abandona-a com facilidade etc.

Neste processo, destacamos a importância do papel da família, ou seja, aquela que se responsabiliza pela educação do sujeito, ou que ainda está envolvida com ele, no caso de adultos. Por meio das técnicas de conversação, onde se estabelece a relação dialógica recuperam-se informações sobre a história da criança, dados sobre o seu desenvolvimento, como ocorreram os primeiros aprendizados, as atividades que criança faz em casa ou na rua, bem como qual é o significado da escola na vida da família e qual a reação dos pais diante dos êxitos e fracassos do aluno. Nessa interação o psicólogo terá a oportunidade de entrar em contato com as características de cada família. Portanto, o trabalho do psicólogo não termina com o retorno aos pais que seus filhos precisam ou não de um atendimento especial, ele precisa ser contínuo, visando a integração da família no processo de escolarização dessas crianças.

A análise das características da criança com ênfase em suas potencialidades de aprendizagem, o processo da avaliação-intervenção poderá colaborar construção de estratégias educacionais junto com os profissionais (psicólogos, professores do ensino regular e especial) para discutirem o planejamento e as formas de intervenção para poderem adequá-los às necessidades da do sujeito. Nessa perspectiva, o psicólogo assume o papel de agente que mobiliza, desmobiliza e organiza o trabalho dentro da escola, averiguando os determinantes sociais da ação do sujeito, principalmente no caso dos alunos que apresentam dificuldades para escolarizar-se. Seguindo esse raciocínio, é preciso conhecimento dos conteúdos que versam sobre o desenvolvimento e humano e dos processos educativos e, sobretudo do método que orienta a sua práxis, nesse caso o método de estudo da unidade de desenvolvimento.

\section{Considerações finais}

Retomando algumas ideias já apresentadas neste artigo, a avaliação psicológica no contexto da educação especial é um processo contínuo, interventivo com objetivo de analisar qualitativamente o que o sujeito é capaz de fazer em diferentes espaços da vida social.
Nesse percurso cabe ao profissional planificar este processo de acordo com as características do sujeito.

Ainda que os sujeitos respondam de formas semelhantes ao mesmo estímulo, há uma complexa trama que implicada na formulação da resposta, pois elas podem ser expressões de sentidos subjetivos adversos. Nessa mesma linha de raciocínio, as denominadas estereotipias de comportamento (comportamentos repetitivos) que são considerados típicos de indivíduos com deficiência, eles possuem uma lógica para aquele que o expressa, portanto, deve ser estudado considerando-o a gênese da sua instalação. Pergunta-se o que o indivíduo quer expressar com seus movimentos repetitivos. Por exemplo, no caso de uma criança com espectro autístico, os rituais não autorregulatórios, portanto, merece investigação de seus nexos na situação social de seu desenvolvimento. Rituais, devaneios e rodeios são atos de criação e possibilitam identificar o movimento da subjetividade do sujeito.

A perspectiva histórico-cultural reconhece 0 indivíduo na sua condição e sujeito que aprende, e, por isso, o método explicativo é adequado para valorizar as manifestações do sujeito mediante as intervenções, onde é possível identificar os limites e as possibilidades de aprendizagem, observando as condições sociais que aprofundam a situação de incapacidade do sujeito com deficiência intelectual. Assim, a avaliação psicológica é processual, interventiva e relacional, opondo-se com o modelo classificatório e quantitativo, tradicional no campo da Educação Especial.

A natureza qualitativa dos processos avaliativos permite construir explicações sobre a particularidade do funcionamento psicológico e sua constituição subjetiva, a qual se desenvolve em meio às condições socioculturais. Por isso é necessário pesquisar o contexto e a qualidade das relações estabelecidas, favorecendo o desenvolvimento de estratégias que visem o aprofundamento das dificuldades decorrente das interações sociais. $\mathrm{O}$ desafio está em estudar as funções psicológicas como sistema articulado no curso da ação do sujeito, identificando as características mediante as diferentes formas de expressão no curso das intervenções.

A avaliação de sujeitos com deficiência intelectual requer maiores investimentos, pois se entende que há necessidade de se construir metodologias específicas para cada situação, conferindo-lhe o status de pesquisa científica, e como tal, requer aprofundamento da compreensão dos processos psicológicos e seus movimentos constitutivos e suas formas de expressões. 
Os investimentos do CFP para alinhar a avaliação psicológica na perspectiva dos Direitos Humanos são dignos de nota, pois muito se avançou na elaboração de normativas para orientar o processo avaliativo considerando os diversos contextos em que ela é empregada. Eles sinalizam para que novos trabalhos ocorram no campo da Educação Especial na perspectiva da Educação Inclusiva, a qual requer estudos e pesquisas de métodos que ofereçam conhecimentos sobre as características psicológicas dos sujeitos, os quais precisam ser considerados partícipes deste processo, o que exigirá mudanças na formação profissional e na organização do sistema educacional brasileiro.

\section{Referências}

American Association on Intellectual and Developmental Disabilities - AAIDD. (2010). Intellectual disability: Definition, classification and systems of supports. Washington, DC: AAIDD.

Aguiar, A. M. B. (2015). Calcanhar de Aquiles: A avaliação do aluno com deficiência intelectual no contexto escolar (Tese de doutorado). Centro de Educação, Universidade Federal do Espírito Santo, Vitória, ES, Brasil.

Anache, A. A. (1997). Diagnóstico ou Inquisição? Estudo sobre o uso do diagnóstico psicológico na escola (Tese de doutorado). São Paulo: Instituto de Psicologia da Universidade de São Paulo, SP, Brasil.

Anache, A. A. (2008). As contribuições da abordagem histórico-cultural para a pesquisa sobre os processos de aprendizagem da pessoa com deficiência mental. In: C. R.Baptista, K. M. Caiado, \& D. M. Jesus. (Orgs.), Educação especial: Diálogo e pluralidade (Vol. 1, pp. 47-58). Porto Alegre, RS: Mediação.

Anache, A. A. (2012). Dimensões subjetivas envolvidas na avaliação da aprendizagem de pessoas com deficiência intelectual. In: M. A. Martinez, B. J. L. Scóz, \& M. I. S. Castanho, Ensino e aprendizagem: A subjetividade em foco (pp. 219-47). Brasília, DF: Liber Livro.

Anache, A. A., \& Corrêa, F. B. (2010). As políticas do Conselho Federal de Psicologia para a avaliação psicológica. In: A. A. Santos, A. A. Anache, A. E. Vellemor-Amaral, B. S. G. Werlang, C. T., C. T. Reppold, C. H. Nunes et al. (Orgs.), Avaliação psicológica: Diretrizes para a regulamentação da profissão (Vol. 1, pp. 19-39). Brasília, DF: Conselho Federal de Psicologia.

Anache, A. A., \& Luz, H. (2014). O lugar da subjetividade no processo de avaliação diagnóstica do indivíduo com deficiência intelectual. In: M. A. Martinez, M. Neubern, \& D. V. Mori, Subjetividade contemporânea: Discussões epistemológicas e metodológicas (pp. 145-146). Campinas, SP: Alínea.

Anache, A. A., \& Nuernberg, H. A. (2015). Sociedade contemporânea, subjetividade e educação especial na perspectiva inclusiva. In: A. A.Anache, B. J. L. Scoz, \& M. I. S. Castanho, Sociedade contemporânea, subjetividade e educação (pp. 54-74). São Paulo, SP: Memnon.

Arce Hai, A. (2018). Educação infantil: Alimentação, neurociência e tecnologia. Campinas, SP: Alínea.

Brasil. Portaria No 142, de 16 de novembro de 2006. Institui o Comitê de Ajudas Técnicas. Diário Oficial da União, 27 nov. 2018 Brasil. Ministério da Educação. (2008). Política nacional de educação especial na perspectiva da educação inclusiva. Brasília, DF: Ministério da Educação.

Calejon, L. M. C., \& Beatón, G. A. (2002). Avaliação psicológica os testes e o diagnóstico explicativo. Piracicaba, SP: Degaspari.

Collares, C. A. L., \& Moysés, M. A. A. (1986). Educação ou saúde? Educação X saúde? Educação e saúde! Cadernos CEDES, (15), 7-16.

Facci, M. G. D., \& Souza, M. P. R. (2014). O processo de avaliação-intervenção psicológica e a apropriação do conhecimento: uma discussão com pressupostos da escola de Vigotski. Revista Psicologia Política, 14(30), 385-403.

Góes, M. C. R. (2000). A abordagem microgenética na matriz histórico-cultural: uma perspectiva para o estudo da constituição da subjetividade. Cadernos CEDES, 20(50), 9-25.

González Rey, F. L. (2012). A configuração subjetiva dos processos psíquicos: Avanços na compreensão da aprendizagem como produção subjetiva. In: M. A. Mitjáns Martinez, B. J. Scoz, \& M. I. S. Castanho, Ensino e aprendizagem: a subjetividade em foco (pp. 21-41). Brasília, DF: Liber Livros. 
González Rey, F. L. (2006). O sujeito que aprende: desafios do desenvolvimento do tema da aprendizagem na psicologia e na prática pedagógica. In: M. C. V. R. Tacca. (Org.), Aprendizagem e trabalho pedagógico (pp. 30-44). Campinas, SP: Alínea.

González Rey, F. L. (2011). Os aspectos subjetivos no desenvolvimento de crianças com necessidades educacionais especiais. In: M. A. Mitjáns Martinez, \& M. C. V. R. Tacca. Possibilidades de aprendizagem: Ações pedagógicas para alunos com dificuldade e deficiência (pp. 48-70). Campinas, SP: Alínea.

Jannuzzi, G. (2004).A educação do deficiente no Brasil. Campinas: Autores Associados.

Kuhnen, R. T. (2017). A concepção de deficiência na política de educação especial brasileira (1973-2016). Revista Brasileira de Educação Especial, 23(3), 329-334. https://dx.doi.org/10.1590/s1413-65382317000300002

Lessa, P. V. (2014). O processo de escolarização e a constituição das funções psicológicas superiores: subsídios para uma avaliação das funções psicológicas superiores (Tese de doutorado). Instituto de Psicologia, Universidade de São Paulo, São Paulo, SP, Brasil.

Luria, A. R. (1981). Fundamentos de neuropsicologia. São Paulo: Editora da Universidade de São Paulo.

Luria, A. R. (1991). Curso de psicologia geral. Rio de Janeiro: Civilização Brasileira.

Machado, A. M. (2002). Avaliação psicológica na educação: mudanças necessárias. In: E. Tanamachi, M. Proença, \& M. Rocha (Orgs.), Psicologia e educação: desafios teórico-práticos (pp.143-167). São Paulo, SP: Casa do Psicólogo.

Mitjáns Martínez, A. (2003) Criatividade e deficiência: por que parecem distantes? Revista Linhas Críticas., 9(16), 73-86.

Patto, M. H. S. (1997). Para uma crítica da razão psicométrica. Psicologia USP, 8(1), 47-62.

Prestes, Z. R. (2010). Quando não é a mesma coisa: análise de traduções de Lev Semionovitch Vygotsky no Brasil: repercussões no campo educacional (Tese de doutorado). Universidade de Brasília, Brasília, DF, Brasil.

Prestes, Z., \& Tunes, E. (2018). Sete aulas de L. S. Vigostki sobre os fundamentos da Pedologia. Rio de Janeiro, RJ: E-papers.

Petrovsky, A. V. (1981). Psicologia general. Havana: Ministerio y Educación.

Resolução No 002, de 23 de março de 2003. Define e regulamenta o uso, a elaboração e a comercialização de testes psicológicos e revoga a Resolução CFP n 025/2001. Brasília, DF: Conselho Federal de Psicologia.

Resolução No 009, de 25 de abril de 2018. Estabelece diretrizes para a realização de Avaliação Psicológica no exercício profissional da psicóloga e do psicólogo, regulamenta o Sistema de Avaliação de Testes Psicológicos - SATEPSI e revoga as Resoluções n 002/2003, n 006/2004 e n 005/2012 e Notas Técnicas nº 01/2017 e 02/2017. Brasília, DF: Conselho Federal de Psicologia.

Salazar, R. M. (1996). O laudo psicológico e a classe especial. Psicologia: Ciência e Profissão, 16(3), 4-11. https://dx.doi.org/10.1590/S1414-98931996000300002

Santos, A. M., Anache, A. A., \& Santana, R. C. (2015). Overview of Brazilian scientific production in psychological evaluation. Psico-USF, 20(3), 547-559. https://ddoi.org/10.1590/1413-82712015200315

Souza, M. P. R. (2000). A queixa escolar na formação de psicólogos: desafios e perspectivas. In: E. R. Tanamachi, M. L. Rocha, \& M. P. R. Proença. (Orgs.), Psicologia e educação: desafios teórico práticos (pp. 105-139). São Paulo, SP: Casa do Psicólogo.

Tezzele, P. C. M. (2017). A produção acadêmica sobre deficiência intelectual (1993 a 2015) (Tese). Ponticia Universidade Católica de São Paulo, São Paulo, SP, Brasil.

Vygotski, L. S. (1984). A formação social da mente. São Paulo, SP: Martins Fontes.

Vygotski, L. S. (1989). Fundamentos de defectologia. Habana: Pueblo y Educación. (Orignalmente publicado em 1924-1929).

Vigotski, L. S. (1987). O desarrollo de las funciones psíquicas superiores. Havana: Editorial Científico Técnica.

Vigotski, L. S. (1996). O método instrumental em Psicologia. In: L. S. Vigotski, Teoria e método em Psicologia (pp. 93-101). São Paulo: Martins Fontes.

Vygotski, L. S. (1997). Obras escogidas: fundamentos da defectologia (Vol. 5, J. G. Blanck, trad). Madrid:Visor. 
Vygotsky, L. S., Luria, A. R. (1996). Estudos sobre a história do comportamento: símios, homem primitivo e criança. Porto Alegre, RS: Artes Médicas.

Alexandra Ayach Anache

Professora Titular da Faculdade de Ciências Humana da Universidade Federal de Mato Grosso do Sul, Campo Grande - MS. Brasil.

E-mail: alexandra.anache@gmail.com

Endereço para envio de correspondência:

Rua Jaguarão, 660, Monte Castelo. CEP: 79010160.

Recebido 20/07/2018

Aprovado 07/08/2018

Received $07 / 20 / 2018$

Approved 08/07/2018

Recibido 20/07/2018

Aceptado 07/08/2018

Como citar: Anache, A. A. (2018). Avaliação Psicológica na Educação Especial na Perspectiva da Educação Inclusiva.Psicologia: Ciência e Profissão, 38(n.spe), 60-73. https://doi.org/10.1590/1982-3703000208800

How to cite: Anache, A. A. (2018).Psychological Assessment in Special Education in the Perspective of Inclusive Education. Psicologia: Ciência e Profissão, 38(n.spe), 60-73. https://doi.org/10.1590/1982-3703000208800

Cómo citar: Anache, A. A. (2018). Evaluación Psicológica en la Educación Especial en la Perspectiva de la Educación Inclusiva.Psicologia: Ciência e Profissão, 38(n.spe), 60-73. https://doi.org/10.1590/1982-3703000208800 